\title{
Genetic variation in native and translocated populations of the Laysan finch (Telespiza cantans)
}

\author{
ROBERT C. FLEISCHER, $*$ SHEILA CONANT† \& MARIE P. MORIN $\ddagger$ \\ *Department of Biology, University of North Dakota, Grand Forks, ND 58202, USA, $\dagger$ Department of General Science, \\ University of Hawaii at Manoa, Honolulu, HI 96822, USA and $\ddagger$ Department of Zoology, University of Hawaii at Manoa,
}

Honolulu, HI 96822, USA

\begin{abstract}
Population size reductions are usually expected to result in decreases of within-population genetic variation. We here report on allozyme variation in (1) the endemic population of the Laysan finch (Telespiza cantans) that was reduced by a major population crash during the early 1900 s and (2) translocated populations on three islets of a distant atoll (Pearl \& Hermes Reef). These populations resulted from the introduction of 108 birds to one islet in 1967 and subsequent dispersal to the other islets. Variation in 33 allozyme loci on Laysan was found to be lower than the average in avian populations, matching theoretical expectation. Unexpectedly, the average heterozygosity of Pearl \& Hermes populations is higher than at Laysan, and significantly so for two of five polymorphic loci. Variation in allele frequencies is relatively high for avian populations $\left(F_{\mathrm{ST}}=0.049\right)$, both among the islets of $\mathrm{P} \& \mathrm{H}$, and between $\mathrm{P} \& \mathrm{H}$ and Laysan. This suggests that isolation within the tiny, translocated populations has resulted in a significant level of genetic differentiation during a relatively short time period (less than 20 years).
\end{abstract}

Keywords: allozymic variation, Bottlenecks, founder effects, population differentiation.

\section{Introduction}

The potential of genetic founder effects to be accompanied by significant genetic differentiation is presently unclear (Carson \& Templeton, 1984; Barton and Charlesworth, 1984). Qualitative (e.g. Mayr, 1954, 1970; Carson, 1971, 1982; Templeton, 1980) and quantitative (Lande, 1980; Charlesworth \& Smith, 1982; Goodnight, 1987, 1988) polygenic models of founder effect have often provided ambiguous results. For example, the intensity of a founder effect depends in part on whether epistatic or only additive variance plays a role within the model (Templeton, 1980; Goodnight, 1987). In addition, founder effects may actually result in increased within-deme genetic variance under certain conditions (Goodnight, 1987, 1988). On the other hand, single-locus population genetic theory clearly predicts that a reduction in population size associated with a founder event will reduce the number of alleles per locus, decrease the heterozygosity $(\mathrm{H})$ and modify the allele frequencies in the founder population relative to the source population (Wright, 1931; Ewens, 1972; Nei et al., 1975; Chakraborty \& Nei, 1977; Maruyama \& Fuerst, 1984, 1985a, b).
Despite the large theoretical base outlined above, there are few empirical demonstrations of founder effects accompanying founder events in natural or artificial populations (see Carson \& Templeton, 1984; Barton \& Charlesworth, 1984, for reviews). In some studies of organisms introduced by man, predictions of single-locus theory have been compared to empirically derived assessments of genetic differences between ancestral and founder populations. Allozyme data have often, at least qualitatively, matched expectation (e.g., Schwaegerle \& Shall, 1979; Esteal, 1985; Parkin \& Cole, 1985; Baker \& Moeed, 1987; Fleischer et al., in press).

In this paper we assess allozyme variation in populations of the Laysan finch, a Hawaiian honeycreeper endemic to Laysan Island. This endemic population underwent a severe bottleneck in the early $1900 \mathrm{~s}$ and genetic variation in Laysan finches should be, and is, lower than that found for populations of other taxa for which no recent bottleneck is known. Allozyme allele frequencies and heterozygosities from Laysan are also compared to populations of the Laysan finch derived from an introduction made in 1967 to one islet of Pearl \& Hermes Reef $(\mathrm{P} \& \mathrm{H})$. Unexpectedly, intrapopulation 
allozyme heterozygosity was found to have increased following the founder event. Interpopulational variation among three islets of $\mathrm{P} \& \mathrm{H}$ is also assessed. These empirical determinations are discussed in relation to the expectations of single locus theories of founder effects.

\section{History of distribution}

Laysan finches are known as fossils from the islands of Molokai and Oahu in the Hawaiian archipelago (Olson \& James, 1982), but are known historically only from Laysan Island (Conant, 1988). The population of finches on Laysan may have been rather stable until the early 1900 s, when rabbits denuded much of the vegetation on the island (Ely and Clapp, 1973). During this period of crisis, the number of finches on Laysan decreased dramatically, from perhaps as many as 2700 in 1911 (Dill \& Bryan, 1912) to the point where in 1923 there were no more than 'a few dozen' (Wetmore, 1925 ) to 'only a few' (Wilder, 1924) individuals remaining. The population increased after extermination of the rabbits in 1923 to a 'conservative estimate' of 1000 in 1936, based on a letter by W. F. Coultas in US Fish and Wildlife Service files. By 1958 the finch population reached about 10,000 birds, and it appears to have stabilized (Ely \& Clapp, 1973). A bottleneck of the size that this population went through, even given the rather rapid recovery following the demise of the rabbits, should result in a moderate loss of genetic variation (Nei et al., 1975; Maruyama \& Fuerst, 1984, $1985)$. Allozyme heterozygosity and allelic diversity is expected to be lower for Laysan finches on Laysan than for species of birds which have not undergone a severe, recent bottleneck.

In March 1967, 58 male and 50 female Laysan finches were introduced to Southeast Island of Pearl \& Hermes Reef from Laysan (Sincock \& Kridler, 1977). The birds were introduced as 'insurance' that the Laysan finch would not become extinct in the event of an additional disaster on Laysan. Pearl \& Hermes Reef is an atoll with several small islands, four of which presently have vegetation sufficient to support Laysan finches: Southeast, North, Grass and Seal-Kittery (Fig. 1). By May and June 1967, the introduced population on Southeast Island had dropped to 30-50 birds (Amerson et al., 1974). The population then grew to about 500 individuals, where it remains today (US Fish and Wildlife Service, 1984), and finches gradually spread to the three other islets listed above (Amerson et al., 1974). The number of founder finches on Southeast Island was not small and the population grew rapidly. Thus, we predict, based on results of Nei et al. (1975), that the finch population on Southeast Island should have slightly lower $H$ than the ancestral population on Laysan.

The sizes of finch populations on each of the islets was monitored from year to year. A natural colonization of Grass Island in 1968 by at least two birds was assisted by an introduction of six birds taken from Southeast Island in 1970. North Island was colonized, probably by only two individuals, in 1973. It is not certain if there were additional movements of birds to North Island. However, of over 908 recaptures and resightings of banded finches during the past five years, there was only one probable case of interislet dispersal, a Seal-Kittery resighting of a bird banded on Grass (Conant, in preparation). Grass and Seal-Kittery are less than $2 \mathrm{~km}$ apart (Fig. 1), so interislet movements may be more likely between them than between other pairs of islets. Because populations on islets other than Southeast had very small founding inoculi, are isolated, and have relatively small-sized populations (50-200 birds; US Fish and Wildlife Service, 1984), we predict that they should have lower $H$ than birds on Southeast and exhibit considerable among-population allele frequency differentiation.

\section{Materials and methods}

\section{Field protocol}

Laysan finches were caught by mist net, potter trap, or hand net for banding, measuring and sampling of blood (see Conant, 1988 for banding protocol). Birds were bled from a wing vein according to the protocol of Wingfield and Farner (1976). A maximum of about $200 \mu \mathrm{l}$ of blood was drawn from each bird. Blood samples were separated into plasma and erythrocyte portions in a hand-cranked centrifuge and then placed into a propane-fueled freezer or liquid nitrogen for a maximum of four weeks. Samples were transported to the ship on ice $(<1 \mathrm{~h})$, where they were placed in $-20^{\circ} \mathrm{C}$ freezer or liquid nitrogen until their return to the laboratory, where they were stored at $-30^{\circ} \mathrm{C}$ until electrophoresis. In total, 90 finches were bled in 1986 and 46 in 1987. The samples included 39 individuals from Laysan Island, 36 from Southeast Island, 31 from North Island and 30 from Grass Island.

\section{Laboratory protocol}

Blood samples were subjected to horizontal starch gel electrophoresis. A total of 24 enzymes or general proteins were assayed. These were malate dehydrogenase (two loci resolved), isocitrate dehydrogenase (two loci), glycerophosphate dehydrogenase, esterase (four loci), glucose-phosphate isomerase (two loci), 


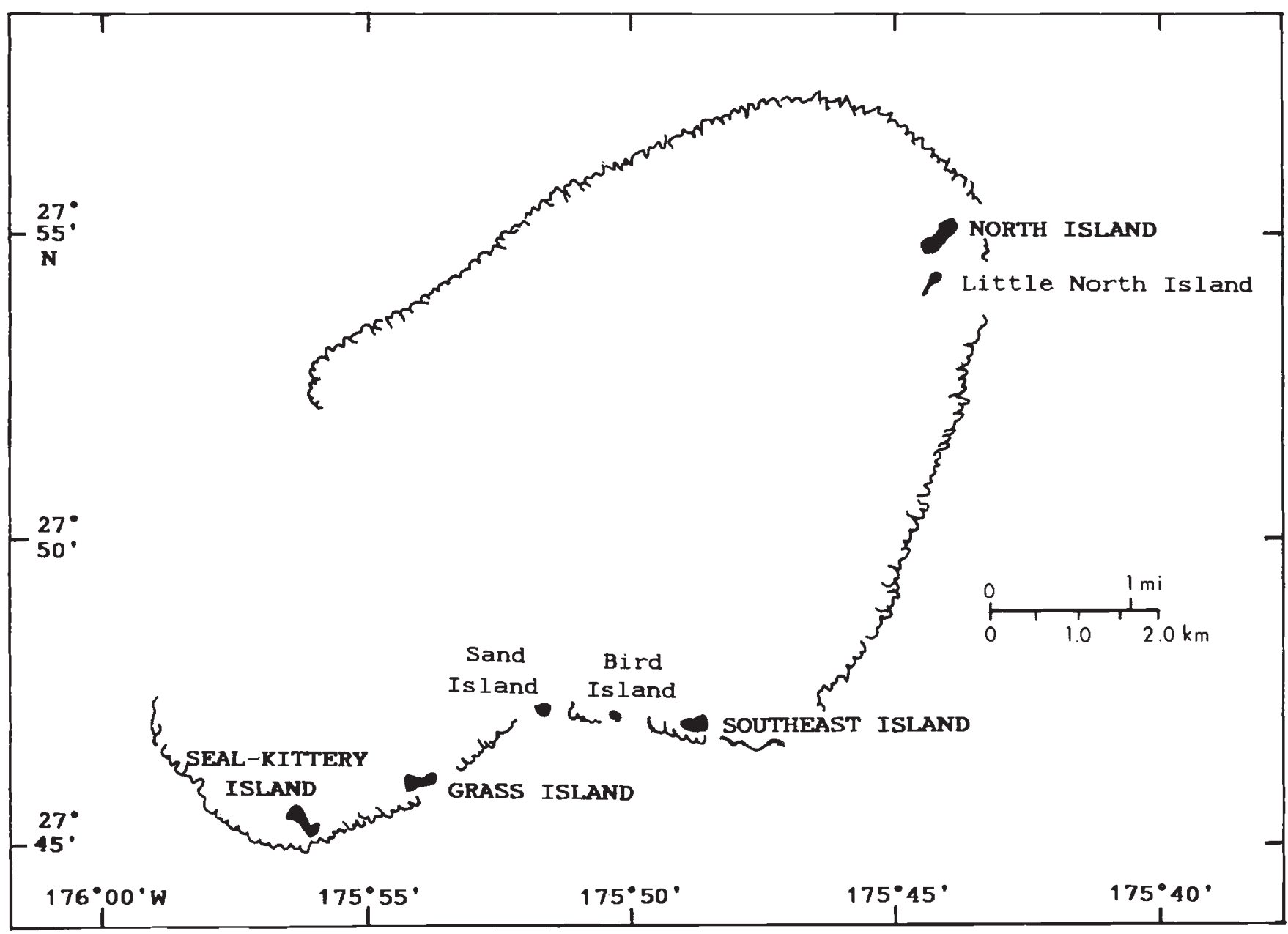

Fig. 1 Map showing the locations of the islets of Pearl \& Hermes Reef $(\mathrm{P} \& H)$. The islets sampled in this study were Southeast, North and Grass. Seal-Kittery also has a population of finches.

phosphoglucomutase (two loci), creatine kinase, glucose-6-phosphate dehydrogenase, lactate dehydrogenase ( 2 loci), dipeptidase (two loci), tri-peptidase, glutamate oxalate transaminase, leucine amino peptidase, 6-phosphogluconic dehydrogenase, malic enzyme, erythrocytic acid phosphatase, mannose-6phosphate isomerase, adenylate kinase, nucleoside phosphorylase, superoxide dismutase, glutamate dehydrogenase, hemoglobin, transferrin, and hexokinase.

We attempted an average of 2.5 buffer systems per staining system. In total, 33 staining regions were successfully resolved and interpreted as products of genetic loci. Of these, only 5 (15.2 per cent) were polymorphic and had staining patterns which appeared consistent with a genetic basis. Buffer systems that were used to resolve these polymorphisms are the discontinuous tris-citrate (for EST-1 and PEPD-2), tris- maleate (for GPI-1), and phosphate (for MDH-1) buffers of Selander et al. (1971), and the phosphatecitrate (for 6-PGD) of Cole \& Parkin (1981). Putative genotypes of the polymorphic enzymes were scored from each gel, with the most anodal locus and allele designated as ' 1 ' and ' $a$ ', respectively. Genotype frequencies were analysed with BIOSYS-1 (Swofford \& Selander, 1981). Allele frequencies were computed and the counted heterozygosities were compared to ones based on Hardy-Weinberg prediction for each locus and island. Heterozygosities and allele frequencies at each locus were compared among islands by contingency table analyses and $G$-tests. Heterozygosities for each sample were averaged over the five polymorphic loci and all loci and compared statistically among samples. Allele frequencies were also assessed for differentiation among samples by calculations of $F_{\text {ST }}$ (Swofford \& Selander, 1981). 


\section{Results}

Sample sizes and allele frequencies for each locus and island are presented in Table 1. Actual values of $H$ do not differ significantly from Hardy-Weinberg expectation for any locus among any of the four samples (no $P<0.08)$. $H$ was averaged over all 33 loci and over only the five polymorphic loci for each of the four sampling sites (Table 2). $H$ values are generally low: the mean $H$ for the sample from Laysan is 1.1 per cent. $H$ is higher in the sample from Southeast Island than in the sample from Laysan Island for all five polymorphic loci, and significantly higher for two (GPI, $G=4.7$, $P<0.05$; EST-1, $G=10.2, P<0.001)$. Mean values of $H$ (averaged over 33 loci) are not significantly different by Mann-Whitney $U$ test between Southeast and Laysan Islands $(U=520, Z=0.53, P=0.60$; Table 2). Values of $H$ at North and Grass Islands, although lower, are also not significantly different from $H$ at Southeast (North, $U=527, Z=0.38, P=0.71$; Grass, $U=510, Z=0.78, P=0.43$ ).

Allele frequencies of three loci vary significantly among the four island samples (Table 3). Allele frequencies of the same three loci also differ significantly

Table 1 Sample sizes and allele frequencies for each of the five polymorphic loci for Laysan and three islets of Pearl \& Hermes Reef (Southeast, North and Grass). The five loci are erythrocyte esterase-1 (EST-1), malate dehydrogenase-1 (MDH-1), glucose-phosphate isomerase (GPI-1), dipeptidase-2 (PEPD-2) and 6-phosphogluconate dehydrogenase (6-PGD)

\begin{tabular}{lllll}
\hline & Laysan & Southeast & North & Grass \\
\hline $\mathrm{N}$ & 39 & 36 & 31 & 30 \\
$\mathrm{EST}-1$ & & & & \\
$\mathrm{a}$ & 0.038 & 0.125 & 0.000 & 0.054 \\
$\mathrm{~b}$ & 0.949 & 0.750 & 0.677 & 0.875 \\
$\mathrm{c}$ & 0.013 & 0.125 & 0.323 & 0.071 \\
$\mathrm{MHD}-1$ & & & & \\
$\mathrm{a}$ & 0.026 & 0.086 & 0.000 & 0.000 \\
$\mathrm{~b}$ & 0.974 & 0.914 & 1.000 & 1.000 \\
GPI-1 & & & & \\
$\mathrm{a}$ & 0.000 & 0.015 & 0.081 & 0.000 \\
$\mathrm{~b}$ & 0.014 & 0.103 & 0.016 & 0.052 \\
$\mathrm{c}$ & 0.986 & 0.882 & 0.903 & 0.948 \\
PEPD-2 & & & & \\
$\mathrm{a}$ & 0.917 & 0.833 & 0.861 & 0.917 \\
$\mathrm{~b}$ & 0.083 & 0.167 & 0.139 & 0.083 \\
6-PGD & & & & \\
$\mathrm{a}$ & 0.000 & 0.029 & 0.017 & 0.000 \\
$\mathrm{~b}$ & 1.000 & 0.971 & 0.983 & 1.000 \\
\hline
\end{tabular}

Table 2 Heterozygosities ( \pm standard deviations) for each island averaged over the five polymorphic loci and over all 33 loci

\begin{tabular}{lcl}
\hline Island & $H(5$ loci $)$ & $H(33$ loci $)$ \\
\hline Laysan & $7.0 \pm 6.6$ & $1.1 \pm 3.5$ \\
Southeast & $20.5 \pm 13.0$ & $3.1 \pm 8.8$ \\
North & $19.5 \pm 23.1$ & $2.9 \pm 10.8$ \\
Grass & $10.4 \pm 10.8$ & $1.6 \pm 5.4$ \\
\hline
\end{tabular}

Table 3 Contingency analyses testing heterogeneity of allele frequencies over islets of $\mathrm{P} \& \mathrm{H}$ and $\mathrm{P} \& \mathrm{H}$ plus Laysan, and $F_{\text {ST }}$ values calculated over all four islet or island samples. Numbers in columns 2 and 3 are values of $\chi^{2}$, with associated significance levels

\begin{tabular}{lccc}
\hline Locus & P\& H Only & All islands & $F_{\text {ST }}$ \\
\hline EST1 & $25.54^{* * *}$ & $43.61^{* * *}$ & 0.084 \\
MDH-1 & $12.45^{* * *}$ & $12.50^{* *}$ & 0.045 \\
GPI-1 & $12.47^{* * *}$ & $19.50^{* *}$ & 0.030 \\
PEPD-2 & 1.13 & 1.67 & 0.013 \\
6-PGD & 2.50 & 4.52 & 0.013 \\
\hline
\end{tabular}

$* * P<0.01$.

*** $P<0.001$.

among only the islets of Pearl \& Hermes Reef (Table 3). These differences are reflected in the relatively high $F_{\text {ST }}$ values for the comparison among all samples (Table 3). Average $F_{\mathrm{ST}}$ for these five loci is 0.049 , indicating a moderate amount of genetic differentiation.

\section{Discussion}

\section{Effects of the bottleneck on Laysan}

The percentage of loci that are polymorphic (15.2 per cent) is only slightly lower than that found for birds in general (about one-third of the examples of Evans, 1987, are less than 15.2 per cent and he calculates a mean $P$ of 24.0 per cent). However, the average $H$ on Laysan (1.1 per cent) is considerably lower than the average $H$ reported for birds in previous studies (4.8 per cent, Nevo, 1978; 4.4 per cent, Evans, 1987). This lower $H$ may have been caused by chance fixation of alleles and inbreeding that must have followed the population crash during the early 1900s. However, earlier bottlenecks or other factors may have also played a role in keeping variability low in this population. The very low heterozygosity and number of alleles do match our expectations from single locus theory (Nei et al., 1975; Maruyama \& Fuerst 1984, 
1985), and the results of some other electrophoretic analyses of populations that have undergone a severe recent bottleneck (e.g. Bonnel \& Selander, 1974; Schwaegerle \& Schall, 1979; Baker \& Moeed, 1987).

\section{The founder effect on Southeast}

We predicted that the population reduction following translocation would result in a slight loss of heterozygosity and number of alleles in the finch population on Southeast. We instead found a slight increase in allelic diversity, a significantly increased heterozygosity for two loci, and a threefold increase in average heterozygosity over 33 loci. Given the small number of polymorphic loci we found, the discrepancy may simply be a result of sampling error. In other words, allele frequencies may have 'drifted up' rather than down for a small fraction of loci, including two of those we assayed by chance. Thus these results may simply underscore the need for a considerably larger sample of allozyme or other loci for calculating and comparing heterozygosities.

An alternative and presently unexcludable explanation is that selection caused the increased $H$ at these or at other linked loci. In one scenario, inbreeding depression in the small inoculum may have resulted in greater survival of outbred, heterozygous individuals, and, therefore, increased heterozygosity (Hayman \& Mather, 1953; Connor \& Belluci, 1979). Alternatively, balancing selection may have occurred directly on the allozyme loci in question, causing $H$ to increase. Conditions may be more rigorous at Pearl \& Hermes Reef than they are at Laysan, both because of its more northerly location and its sparser, more open habitat.

A number of previous field studies with historical information on founder events (e.g. Ross, 1983; Parkin \& Cole, 1985; Janson, 1986; Baker \& Moeed, 1987; Fleischer et al., in press) have generally found only minor (if any) decreases in $H$ following founder events. Instead, most of these studies report only the loss of rare alleles. No study using allozymes, to our knowledge, has discovered an increased $H$ following a natural or experimental bottleneck or founder event.

\section{Variability at Pearl \& Hermes Reef}

Heterozygosity should be lower on North and Grass Islands than on Southeast because only a small number of birds colonized North and Grass, gene flow appears to be extremely rare, and population sizes are much smaller. Overall heterozygosity did not differ significantly among the islets of Pearl \& Hermes Reef, but was somewhat lower on Grass Island than on Southeast. This suggests that although populations on the islets would appear to be highly inbred and prone to drift, relatively little loss of allozymic heterozygosity has occurred.

This result runs somewhat counter to expectation and to the results of the comparison of allele frequencies. Significant heterogeneity of allele frequencies has evolved among the introduced populations at $\mathrm{P} \& \mathrm{H}$ and among all of the island populations (Tables 1 and 3). The mean $F_{\mathrm{ST}}$ value of 0.049 is nearly identical to the mean value $(0.048)$ for 23 species of birds as calculated by Evans (1987). It is also higher than many of the values cited in Barrowclough \& Johnson (1988, Table 1): the average $F_{\mathrm{ST}}$ for species for which morphologically differentiated subspecies were compared was 0.054 , the average for species with relatively low phenotypic variability (as is the case for the Laysan finch; Conant, 1988) was 0.007. Most of the species summarized in these studies were sampled over a much wider geographic range than that of the Laysan Finch. In addition, virtually all the species have been in their present ranges for a considerably longer time period than 20 years. Thus the Laysan finch has apparently evolved a moderate amount of microgeographic heterogeneity over a relatively short period of time, presumably because of isolation from gene flow and drift. It will be interesting to monitor these populations for additional changes in genetic and morphological (Conant, 1988) variation in the future.

\section{Acknowledgements}

We thank the National Marine Fisheries Service, the US Fish and Wildlife Service, and the National Science Foundation (BSR-8516702) for logistical and/or financial support of this research. C. McIntosh and L. Miller assisted in the laboratory. We thank H. Carson, M. Soule and an anonymous reviewer for their helpful comments on the meaning (or lack thereof) of these results.

\section{References}

AMERSON, A. B., ClAPP, R. B. AND WIRTZ, w. o. 1II. 1974. The natural history of Pearl \& Hermes Reef, Northwestern Hawaiian Islands. Atoll Res. Bull., No. 174.

BAKER, A. J. AND MOEED, A. 1987. Rapid genetic differentiation and founder effect in colonizing populations of common mynas (Acridotheres tristis). Evolution, 41, 525-538.

BARRowClOUGH, G. F. AND Johnson, N. K. 1988. Genetic structure of North American birds. In Acta XIX Congressus Internat. Ornithol., pp. 1630-1645. Univ. of Ottawa Press. BARTON, N. AND CHARLESWORTH, B. 1984. Genetic revolutions, founder effects and speciation. A. Rev. Ecol. Syst., 15, 133-164. 
BONNELL, M. L. AND SELANDER, R. K. 1974. Elephant seals: genetic variation and near extinction. Science, 184, 908-909.

CARSON, H. L. 1971. Speciation and the founder principle. Stadler Genet. Symp., 3, 51-70.

CARSON, H. L. 1982. Speciation as a major reorganization of polygenic balances. In Barigozzi, C. (ed.) Mechanisms of Speciation, Liss, New York.

CARSON, H. L. AND TEMPLETON, A. R. 1984. Genetic revolutions in relation to speciation phenomena: the founding of new populations. A. Rev. Ecol. Syst., 15, 97-131.

CHAKRABORTY, R. AND NEI, M. 1977. Bottleneck effects on average heterozygosity and genetic distance with the stepwise mutation model. Evolution, 31, 347-346.

CHARLESWORTH, B. AND SMITH, D. B. 1982. A computer model of speciation by founder effects. Genet. Res., 39, 227-236.

COLE, S. R. AND PARKIN, D. T. 1981. Enzyme polymorphism in the house sparrow, Passer domesticus. Biol. J. Linn. Soc., 15, 12-22.

CONANT, s. 1988. Geographic variation in the Laysan finch (Telespiza cantans). Evol. Ecol., 2, 270-282.

CONNOR, J. L. AND BELLUCI, M. J. 1979. Natural selection resisting inbreeding depression in captive wild housemice (Mus musculus). Evolution, 33, 929-940.

DILL, H. R. AND BRYAN, w. A. 1912. Report of an expedition to Laysan Island in 1911. U.S.D.A. Biol. Surv. Bull., 42.

ELY, C. A. AND CLAPP, R. B. 1973. The natural history of Laysan Island, Northwestern Hawaiian Islands. Atoll Res. Bull. No. 171.

ESTEAL, s. 1985. The ecological genetics of introduced populations of the giant toad Bufo marinus. II. Effective population size. Genetics, 110, 107-122.

EVANS, P. G. H. 1987. Electrophoretic variability of gene products. In Cooke, F. and Buckley, P. A. (eds) Avian Genetics, Academic Press, London.

EWENS, w. J. 1972. The sampling theory of selectively neutral alleles. Theoret. Pop. Biol., 3, 87-112.

FLEISCHER, R. C., WILlIAMS, R. N. AND BAKER, A. J. M. S. Genetic variation within and among Hawaiian populations of the common myna (Acridotheres tristis). J. Heredity (in press).

GOODNIGHT, C. J. 1987. On the effects of founder events on epistatic genetic variance. Evolution, 41, 80-91.

GoODNIGHT, C. J. 1988. Epistasis and the effect of founder events on the additive genetic variance. Evolution, 42, 441-454.

HAYMAN, B. I. AND MATHER, K. 1953. The progress of inbreeding when homozygotes are at a disadvantage. Heredity, 7, 165-183.

JANSON, K. 1987. Genetic drift in small and recently founded populations of the marine snail Littorina saxatilis. Heredity, 58, 31-37.

LANDE, R. 1980. Genetic variation and phenotypic evolution during allopatric speciation. Am. Nat., 116, 463-479.

MARUYAMA, T. AND FUERST, P. A. 1984. Population bottlenecks and nonequilibrium models in population genetics. I. allele numbers when populations evolve from zero variability. Genetics, 108, 745-763.

MARUYAMA, T. AND FUERST, P. A. 1985. Population bottlenecks and nonequilibrium models in population genetics. II. Number of alleles in a small bottleneck that was formed by a recent bottleneck. Genetics, 111, 675-689.

MAYR, E. 1954. Change of genetic environment and evolution. In Huxley, J. (ed) Evolution as a Process, Allen and Unwin, London.

MaYr, E. 1970. Populations, Species, and Evolution. Harvard University Press, Cambridge, Massachusetts.

NEI, M., MARUYAMA, T. AND CHAKRABORTY, R. 1975. The bottleneck effect and genetic variability in populations. Evolution, 29, 1-10.

NEvo, E. 1978. Genetic variation in natural populations: pattern and theory. Theor. Pop. Biol., 13, 121-177.

OLSON, S. L. AND JAMES, F. F. 1982. Prodromus of the fossil avifauna of the Hawaiian Islands. Smithsonian Contrib. Zool., 365, 1-59.

Ross, H. A. 1983. Genetic differentiation of starling (Sturnus vulgaris: Aves) populations in New Zealand and Great Britain. J. Zool. Lond, , 201, 351-352.

PARKIN, D. T. AND COLE, S: R. 1985 . Genetic differentiation and rates of evolution in some introduction populations of the House Sparrow, Passer domesticus, in Australia and New Zealand. Heredity, 54, 15-23.

SCHWAEGERLE, K. E. AND SHALL, B. A. 1979. Genetic variability and founder effect in the pitcher plant Sarracenia purpurea L. Evolution, 33, 1210-1218.

SELANDER, R. K., SMITH, M. H., YANG, S. Y., JOHNSON, W. E. AND GENTRY, J. B. 1971. Biochemical polymorphism and systematics in the genus Peromyscus. I. Variability in the old-field mouse (Peromyscus polionotus). Univ. Texas Public., 7103, 49-90.

SINCOCK, J. L. AND KRIDLER, E. 1977. The extinct and endangered endemic birds of the Northwest Hawaiian Islands. US Fish and Wildlife Service, Admin. Rept., Honolulu, Hawaii.

SWOFFORD, D. L. AND SELANDER, R. B. 1981. A computer program for the analysis of allelic variation in genetics. $J$. Heredity, 72, 281-283.

TEMPLETON, A. R. 1980. The theory of speciation via the founder principle. Genetics, 94, 1011-1038.

US FISH AND WILDLIFE SERVICE. 1984. Northwestern Hawaiian Islands Passerines Recovery Plan. US Fish and Wildlife Service, Portland, Oregon.

WETMORE, A. 1925. Bird life among lava rock and coral sand. Nat. Geog. Mag., 48, 77-108.

WILDER, G. P. 1924. Extracts from a letter received by the Bureau of Biology Survey on 12 May, 1924. Bureau of Sports Fisheries and Wildlife, Kailua.

WINGFIELD, J. C. AND FARNER, D. s. 1976. Avian endocrinologyfield investigations and methods. Condor, 78, 570-573.

WRIGHT, s. 1931. Evolution in Mendelian populations. Genetics, 16, 93-159. 